\title{
THE XIth INTERNATIONAL CONFERENCE OF SOCIAL WORK MEETS IN BRAZIL
}

At the invitation of the Brazilian National Committee, the XIth International Conference of Social Work was held at Petropolis, near Rio de Janeiro, from August 19 to 24, 1962. More than 2,300 delegates from 56 countries met to exchange experiences in the field of community development.

It was not by chance that such a subject was chosen. The countries of Latin America are developing rapidly and the principles of what is called community development are of particular interest to them. In a country like Brazil, towns are growing very much faster and new cities such as Brasilia spring up in a few years. The social problems are immense. Pauperism and illiteracy are still considerable. But there reigns a lively spirit of brotherhood, of human understanding and, as in the other Latin American countries, great efforts are being made to develop social work.

Countries which are developing rapidly are certainly interested in community development but the national reports presented at the Conference call attention to the growth and mobility of population. They point out the tensions which result from this and recall that it is becoming essential to set up plans and to provide for a method which will enable the efforts being made in numerous countries to be arranged and unified.

In accordance with tradition, the Conference included a certain number of plenary sessions. Talks on experiments made, in particular in Egypt, Greece, India, Chile, Holland and Canada gave a very realistic character to this congress. Furthermore, committees 
and study groups enabled a more limited number of delegates to tackle certain particular problems, such as rural community development, recruitment, the training and employment of workers, community action on behalf of the sick, the process of planning, relations between the activities of social work and medical activities. Several international organizations took the opportunity of this world assembly to hold meetings. This was the case of the League of Red Cross Societies.

It should first of all be explained what is meant by " community development" which the Conference had chosen for its subject, in its rural and urban aspect. This expression was used for the first time by the British Government in 1942 when it was a question of helping certain countries to prepare for independence and, in 1958, the United Nations proposed a definition of the term : Community development is a process in which people themselves participate in the planning and carrying out of programmes intended to improve their standard of living. It implies close co-operation between the official authorities and the inhabitants.

Despite national efforts to raise the standard of living throughout the world, a recent United Nations publication drew attention to this disturbing fact: In spite of unprecedented progress in the technological and scientific fields and in several economic and social sectors over the last ten years, the number of human beings who suffer from hunger and misery is greater than ever. Even in the field of education where a considerable effort has been made, progress is not satisfactory. As a result of the population explosion, the number of illiterates has not diminished as was hoped, quite the contrary.

How is such a problem to be dealt with ? Community development, because it comprises a method in which the human factor is uppermost, represents an important contribution to the solution of this question. Whether responsibility for it is assumed by a public body or a private body, its essential elements remain the same. They are :

a) Recognition by the population of its own needs, the choice of priorities and the setting up of activities for the improvement in the levels of economic, social and cultural life. 
b) Encouragement of the population to carry out, itself, the plans established on its behalf and to develop the necessary means for their success.

c) The maximum use of local, national and international organizations, the development of local programmes and adaptation of methods to the required objectives.

d) Availability of resources and technical assistance required by the private and public bodies.

e) Integration of the various community plans in a national programme.

A thing which must be particularly emphasized and which is a new development in the sphere of planning is the importance attached to the co-operation of those concerned.

As in casework, it is no longer a question of imposing solutions from on high, but of asking the beneficiaries who, in social work, are called users, for their active participation.

Community development is to enlarge the task of social work, taking into account the needs of the community. In the beginning, the social worker dealt with the individual, then he turned his attention to groups. He acquired the techniques of casework and groupwork. Using these techniques which are themselves based on the respect for his sense of responsibilities, he will put into operation, in community development, the means of satisfying the needs of the masses within any given geographical unit. His action will be determined by the cultural past of the community, its system of values, its economic conditions and the degree of civic education of its population.

None of this can have practical effect without team work with other specialists such as town planners, sociologists and representatives of the local authorities and existing social institutions. The participation of social work will depend in large part on the competence and personality of the social workers, on their ability to adapt themselves to new situations and on their capacity to create and organize human relations. As a result of the professional relations which they have established with people in difficulty they will show, in taking part in community development, a profound understanding of what increasingly rapid change means to the 
individual and his family. The techniques which they employ also enable them to help the users of social work to make constructive use of the process of change with a view to helping them to adapt.

A great responsibility rests with the training schools for social workers who are going to contribute to community development and, in most countries, their study programmes will have to be reviewed in the light of these new requirements.

Numerous ideas were put forward at Petropolis and there were numerous exchanges of views. More than at other conferences, a great spirit of solidarity united social workers from rapidly developing countries and those who benefit from an older tradition of social service. Nobody today can escape from the deep-rooted movement which is transforming the world. Eyes were on the delegates of the young nations where community development, with all that it implies, has become a necessity, and where experience can serve as a lesson.

Finally, it should be pointed out that during the discussions which took place within the study groups as also in the plenary sessions and special meetings, the accent was constantly on the contribution which social work can make to community development. This contribution is affirmed in the following form in the preliminary report established by a working group to demarcate the principal subjects to be discussed at the Conference :

Social work wishes to make an important contribution to community development, which itself can have an important influence on the techniques which social work employs at the present time. Social workers must therefore extend their horizons and their knowledge, learn the economic and social needs of collectivity, assume the responsibility of meeting collective needs, create new services which might prove to be necessary and help to pin-point what social policy should be within each country. The report ends by saying: "Social work has a unique rôle to play in community development".

We can only give some idea, in this short article, of the many aspects of the Conference at Rio de Janeiro. An international conference must be lived, the personal contacts made there are one of the attractions, but to know a country, its problems and its resources constitutes yet another aspect. A day was therefore set 
aside for visits to social institutions. The delegates observed the effectiveness of social services such as those of the S.E.S.I. (Social Service Undertaking), training centres, rural university, re-installation and rehabilitation centres, etc.

The XIth International Conference of Social Work achieved its aim. On the one hand, it enabled participants from countries other than Latin America to get to know a region of the world of whose difficulties they were frequently ignorant. On the other hand, it gave an opportunity to Brazilian social workers to express themselves, to show what they were and what they were doing and, thus, to attract the attention of authorities which henceforth will be better disposed to support them.

The next International Conference will meet in Athens in September 1964. Its theme will be "Social planning and social work" and it will be preceded, in the summer of 1963, by a European " confabulation" in Stuttgart, which will be a form of preparation for the Conference itself.

M. L. CORNAZ

Directress of the School of Social Studies in Geneva 